University of Wollongong

Research Online

Australian Institute for Innovative Materials -

Papers

Australian Institute for Innovative Materials

$1-1-2012$

\title{
Anti and gauche conformers of an inorganic butane analogue, $\mathrm{NH} 3 \mathrm{BH} 2 \mathrm{NH} 2 \mathrm{BH} 3$
}

\author{
Xuenian Chen \\ Ohio State University \\ Judith C. Gallucci \\ Ohio State University \\ Charles Campana \\ Bruker Axs Inc \\ Zhenguo Huang \\ Ohio State University, zhenguo@uow.edu.au \\ Hima Kumar Lingam \\ Ohio State University
}

See next page for additional authors

Follow this and additional works at: https://ro.uow.edu.au/aiimpapers

Part of the Engineering Commons, and the Physical Sciences and Mathematics Commons

Research Online is the open access institutional repository for the University of Wollongong. For further information contact the UOW Library: research-pubs@uow.edu.au 


\title{
Anti and gauche conformers of an inorganic butane analogue, $\mathrm{NH} 3 \mathrm{BH} 2 \mathrm{NH} 2 \mathrm{BH} 3$
}

\begin{abstract}
The crystal structures of an inorganic butane analogue, NH3BH2NH2BH3 (DDAB), were determined using single crystal $\mathrm{X}$-ray diffraction, revealing both anti and gauche conformations. The anti conformation is stabilized by intermolecular dihydrogen bonds in the crystal whereas two gauche conformations of DDAB observed in its 18-crown- 6 adducts are stabilized by an intramolecular dihydrogen bond. The two gauche conformations show rotational isomerization but whether they are a pair of enantiomers is yet to be defined.
\end{abstract}

\section{Keywords}

anti, analogue, nh3bh2nh2bh3, conformers, inorganic, butane, gauche

Disciplines

Engineering | Physical Sciences and Mathematics

\section{Publication Details}

Chen, X., Gallucci, J., Campana, C., Huang, Z., Lingam, H. Kumar., Shore, S. G. \& Zhao, J. (2012). Anti and gauche conformers of an inorganic butane analogue, $\mathrm{NH} 3 \mathrm{BH} 2 \mathrm{NH} 2 \mathrm{BH}$. Chemical Communications, 48 7943-7945.

\section{Authors}

Xuenian Chen, Judith C. Gallucci, Charles Campana, Zhenguo Huang, Hima Kumar Lingam, Sheldon G. Shore, and Ji-Cheng Zhao 


\section{Anti and gauche conformers of an inorganic butane analogue, $\mathrm{NH}_{3} \mathrm{BH} 2 \mathrm{NH} 2 \mathrm{BH} 3$}

ARTICLE in CHEMICAL COMMUNICATIONS · JULY 2012

Impact Factor: $6.83 \cdot$ DOI: 10.1039/c2cc33621a $\cdot$ Source: PubMed

CITATIONS

11

7 AUTHORS, INCLUDING:

\section{Charles Campana}

Bruker Corporation

190 PUBLICATIONS 3,612 CITATIONS

SEE PROFILE

\section{Sheldon G Shore}

The Ohio State University

131 PUBLICATIONS $\quad 2,235$ CITATIONS

SEE PROFILE
READS

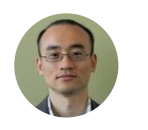

Zhenguo Huang

University of Wollongong

55 PUBLICATIONS 517 CITATIONS

SEE PROFILE

Ji-Cheng Zhao

The Ohio State University

102 PUBLICATIONS 2,628 CITATIONS

SEE PROFILE 


\title{
Anti and gauche conformers of an inorganic butane analogue, $\mathbf{N H}_{3} \mathbf{B H}_{2} \mathbf{N H}_{2} \mathbf{B H}_{3}^{\dagger}$
}

\author{
Xuenian Chen, ${ }^{a b}$ Judith Gallucci, ${ }^{b}$ Charles Campana, ${ }^{c}$ Zhenguo Huang, ${ }^{a}$ \\ Hima Kumar Lingam, ${ }^{b}$ Sheldon G. Shore ${ }^{* b}$ and Ji-Cheng Zhao*a \\ Received 19th May 2012, Accepted 15th June 2012 \\ DOI: $10.1039 / \mathrm{c} 2 \mathrm{cc33621a}$
}

The crystal structures of an inorganic butane analogue, $\mathrm{NH}_{3} \mathrm{BH}_{2} \mathrm{NH}_{2} \mathrm{BH}_{3}$ (DDAB), were determined using single crystal $\mathrm{X}$-ray diffraction, revealing both anti and gauche conformations. The anti conformation is stabilized by intermolecular dihydrogen bonds in the crystal whereas two gauche conformations of DDAB observed in its 18-crown-6 adducts are stabilized by an intramolecular dihydrogen bond. The two gauche conformations show rotational isomerization but whether they are a pair of enantiomers is yet to be defined.

Butane is the archetypical hydrocarbon, serving as the platform for developing an understanding of and the vocabulary for conformational analysis and steric hindrance. Conformational analysis of butane is fundamental to organic chemistry. The rotational barriers and conformation energies in butane are well known, but the interactions governing butane's conformational isomerism are not fully understood. ${ }^{1,2}$

An inorganic butane analogue, $\mathrm{NH}_{3} \mathrm{BH}_{2} \mathrm{NH}_{2} \mathrm{BH}_{3}$ (1,3-diaza2,4-diborabutane, a dehydro-dimer of ammonia borane, DDAB) was first synthesized in good yield at ambient temperature in our laboratory. ${ }^{3}$ Although DDAB and butane are isoelectronic, their physical properties are remarkably different. DDAB is a white crystalline powder that melts at $62{ }^{\circ} \mathrm{C}$ while butane is a gas at room temperature, melting at $-134{ }^{\circ} \mathrm{C}^{3}$ Furthermore, in contrast to butane, theoretical studies predict that the gauche conformation of DDAB is more stable by $12.3 \mathrm{kcal} \mathrm{mol}^{-1}$ at the $\operatorname{CCSD}(\mathrm{T}) / \mathrm{CBS}$ level or $11.2 \mathrm{kcal} \mathrm{mol}^{-1}$ at the B3LYP/6-311+G(2d,p)//B3LYP/6-31G(d) level of theory. ${ }^{4}$ An intramolecular dihydrogen bond accounts for the stability of the gauche form. ${ }^{4 b}$ In studying the unique behaviour of the conformations of DDAB we have discovered the significant role of both intramolecular and intermolecular dihydrogen bonds.

\footnotetext{
${ }^{a}$ Department of Materials Science and Engineering, The Ohio State University, Columbus, Ohio 43210.E-mail: zhao.199@osu.edu

${ }^{b}$ Department of Chemistry, The Ohio State University, Columbus, Ohio 43210.E-mail: shore.1@osu.edu

${ }^{c}$ Bruker AXS Inc., Madison, WI 53711, United States

$\dagger$ Electronic supplementary information (ESI) available: Crystallographic data, bond distances and angles, dihydrogen bond distance, and XRD pattern. CCDC 882868-882869. For ESI and crystallographic data in CIF or other electronic format see DOI: 10.1039/ c2cc33621a
}

Dihydrogen bonds are formed by the interaction of two hydrogen atoms: a positively charged hydrogen, the proton donor, and a negatively charged hydrogen, the proton acceptor. First reported in $1968^{5,6}$ dihydrogen bonds have been identified in a wide range of structures by means of X-ray and neutron diffraction techniques. ${ }^{7}$ The fundamental characteristics of the dihydrogen bonds are well understood. ${ }^{8,9}$ We have recently elucidated the role of dihydrogen bonds in promoting reactivity in a few N,B compounds. ${ }^{3}$ The formation of an intramolecular dihydrogen bond and subsequent molecular hydrogen elimination are the bases of a convenient synthesis of aminodiborane $\left(\mathrm{NH}_{2} \mathrm{~B}_{2} \mathrm{H}_{5}, \mathrm{ADB}\right)$ in a ambient-temperature, catalyst-free reaction between ammonia borane $\left(\mathrm{NH}_{3} \mathrm{BH}_{3}, \mathrm{AB}\right)$ and tetrahydrofuran borane, THF. $\mathrm{BH}_{3} \cdot{ }^{3}$ Dihydrogen bonds also play an essential role in the formation of $\mathrm{AB}$ and the diammoniate of diborane $\left(\left[\mathrm{H}_{2} \mathrm{~B}\left(\mathrm{NH}_{3}\right)_{2}\right]\left[\mathrm{BH}_{4}\right], \mathrm{DADB}\right)$ in the reaction of ammonia with $\mathrm{THF} \cdot \mathrm{BH}_{3},{ }^{10,11}$ and are the bases of our development of a large-scale synthesis of AB by simple displacement reactions. ${ }^{12}$ Here we present another example of the important role of both inter- and intramolecular dihydrogen bonds in determining the conformations of DDAB.

While attempts to grow single crystals of DDAB in various solvents were unsuccessful, single crystals of adducts of DDAB with 18-crown-6 ether were rapidly obtained from a THF solution of DDAB and crown ether at a $1: 1$ ratio. Two types of crystals were successively produced from the same solution. Chunk-shaped crystals formed first, whose crystal structure was reported in our previous communication, ${ }^{3}$ followed by needle-shaped crystals several weeks later. Both polymorphs have the same space group, $P 2_{1} 2_{1} 2_{1}$, but significantly different unit cell parameters (Table S1 $\dagger$ ). DDAB adopts a gauche form in the crown ether adducts, which is consistent with the theoretical results. ${ }^{4}$ Intermolecular dihydrogen bonds, commonly observed in amine boranes, 5,7 were prevented from forming by the bulky crown ether at one end of DDAB (Fig. 1). The $\mathrm{H}^{\delta-}$ of terminal $-\mathrm{BH}_{3}$ at the other end of DDAB bends back to interact with the $\mathrm{H}^{\delta+}$ of the terminal $-\mathrm{NH}_{3}$ to form an intramolecular dihydrogen bond. The $\mathrm{H}^{\delta+} \ldots \mathrm{H}^{\delta-}$ distances, $2.40 \AA$ for the chunk shaped crystals and $2.42 \AA$ for the needle shaped crystals (normalized based on an $\mathrm{N}-\mathrm{H}$ bond of $1.03 \AA$ and a $\mathrm{B}-\mathrm{H}$ bond of $1.21 \AA$ ), ${ }^{7,13}$ are at the upper end of the expected dihydrogen bond range and longer than the predicted $1.925 \AA$ bond length, ${ }^{4 a}$ 
(a)

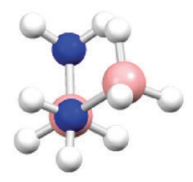

$\left(a^{\prime}\right)$

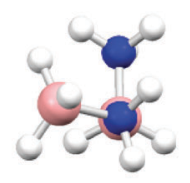

(b)

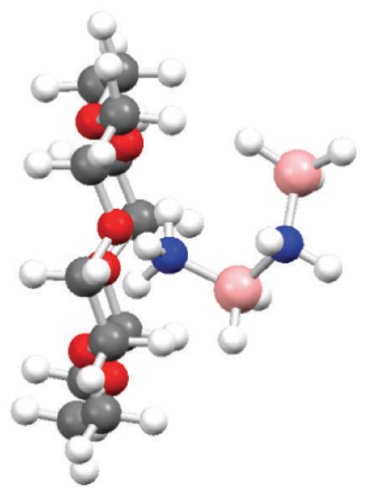

$\left(b^{\prime}\right)$

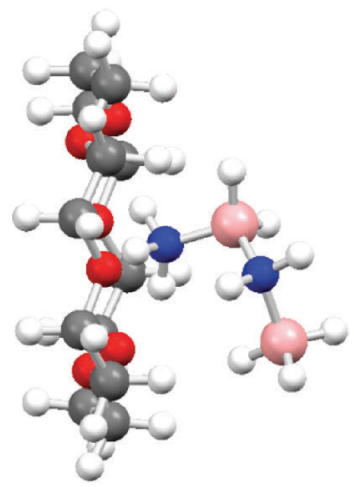

Fig. 1 Two polymorphic crystal structures of 18-crown-6 adducts with $\mathrm{NH}_{3} \mathrm{BH}_{2} \mathrm{NH}_{2} \mathrm{BH}_{3}$. (a) and (a') Newman projections down the N2-B1 bond; (b) and ( $\left.b^{\prime}\right)$ Side views of adducts of DDAB with crown ether (N: blue, B: orange, H: light gray, O: red, C: dark gray).

possibly because the classical hydrogen bonds between $-\mathrm{NH}_{3}$ and the crown ether compete with the dihydrogen bond.

Fortunately, a single crystal of DDAB was found from a powder sample and its crystal structure was determined by $\mathrm{X}$-ray single crystal diffraction analysis. It belongs to the monoclinic Pn space group (Table S1†). All N-B bond distances and bond angles are comparable with those observed

in the gauche form and other reported $\mathrm{B}-\mathrm{N}$ chain anion compounds, ${ }^{14-17}$ and fall within the normal range (Table S2 $\dagger$ ). The striking feature of the molecular structure is that DDAB adopts an anti, rather than gauche, conformation (Fig. 2a), in contradiction to the theoretical prediction. ${ }^{4}$ Each DDAB molecule is involved with a total of 24 dihydrogen bonds with its nearest neighbours with the shortest $\mathrm{H} \cdots \mathrm{H}$ distance of $2.02 \AA$ and the longest of $2.38 \AA$ (Fig. $2 b$ and Table $S 3 \dagger$ ). The extensive dihydrogen bond formation stabilizes the anti form and is not accounted for in the theoretical prediction of the crystal structure of DDAB. ${ }^{4}$

Although the crystal structure was determined from only one single crystal picked out of the powder sample, the exact agreement of the X-ray powder pattern of the bulk sample with the simulated pattern from the single crystal structure indicates the powder sample of DDAB has the same structure (Fig. S1†).

To date four structures of three substituted B-N butane analogues have been determined, three free $\mathrm{B}-\mathrm{N}$ butane analogues, $\mathrm{Me}_{2} \mathrm{NHBH}_{2} \mathrm{NMe}_{2} \mathrm{BH}_{3} \quad(\mathrm{I}){ }^{14} \quad\left(1,4-\mathrm{C}_{4} \mathrm{H}_{8}\right)$ $\mathrm{NHBH}_{2} \mathrm{~N}\left(1,4-\mathrm{C}_{4} \mathrm{H}_{8}\right) \mathrm{BH}_{3}$ (II) ${ }^{15}$ and $\mathrm{MeNH}_{2} \mathrm{BH}_{2} \mathrm{NHMeBH}_{3}$ (III), ${ }^{16}$ and a coordinated one in compound, $\left[\operatorname{Ir}\left(\mathrm{PCy}_{3}\right)_{2}(\mathrm{H})_{2}-\right.$ $\left.\left(\eta^{2}-\mathrm{H}_{3} \mathrm{BNHMeBH}_{2} \mathrm{NH}_{2} \mathrm{Me}\right)\right]\left[\mathrm{BAr}{ }_{4}^{\mathrm{F}}\right]$ (IV). ${ }^{16}$ In these structures, free $\mathrm{MeNH}_{2} \mathrm{BH}_{2} \mathrm{NHMeBH}_{3}$ adopts anti (III) form and all others adopt gauche form (Table $\mathrm{S} 4 \dagger$ ). Intermolecular dihydrogen bonds were observed in structures I and II as well as dimeric structures of the two gauche forms; ${ }^{14,15}$ and an intramolecular dihydrogen bond was observed in structure IV. ${ }^{16}$ Neither internor intramolecular dihydrogen bonds were found in the anti form (III). ${ }^{16}$ Substituents complicate the factors governing conformations in the structures of the butane analogues. Herein we report for the first time both anti and gauche conformers of the unsubstituted B-N butane analogue, DDAB. Intermolecular dihydrogen bonds stabilize the anti form and an intramolecular dihydrogen bond stabilizes the gauche form.

The correlation of inter/intramolecular dihydrogen bonds with conformation is also observed in the chain structures (a)

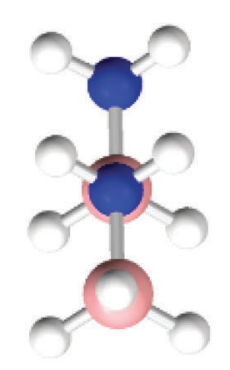

(b)

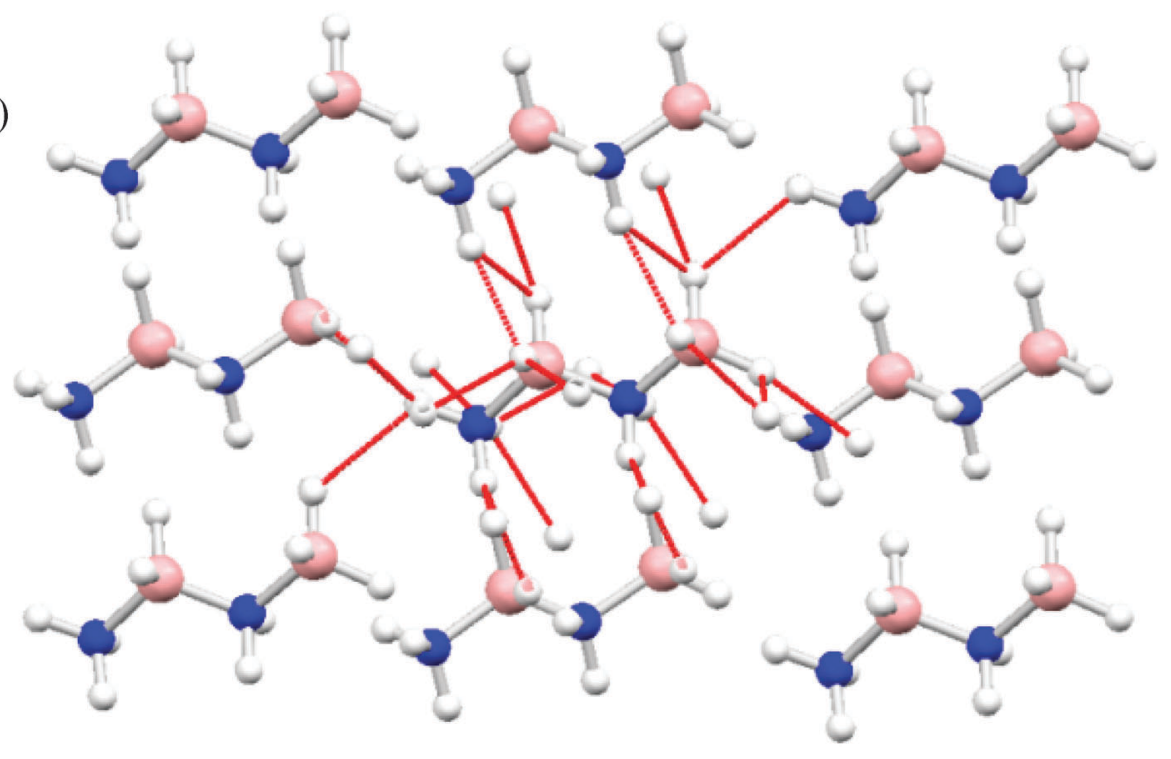

Fig. 2 Anti-conformer of $\mathrm{NH}_{3} \mathrm{BH}_{2} \mathrm{NH}_{2} \mathrm{BH}_{3}$ (a) Newman projection down the $\mathrm{N} 2-\mathrm{B} 1$ bond; (b) intermolecular dihydrogen bonds (N: blue, B: orange and $\mathrm{H}$ : light gray). 
of anionic borane-capped ammonia borane oligomers, $\mathrm{VBH}^{+}\left[\mathrm{H}_{3} \mathrm{BNH}_{2} \mathrm{BH}_{2} \mathrm{NH}_{2} \mathrm{BH}_{3}\right]^{-}(\mathrm{V})$ and $\mathrm{VBH}^{+}\left[\mathrm{H}_{3} \mathrm{BNH}_{2} \mathrm{BH}_{2}-\right.$ $\left.\mathrm{NH}_{2} \mathrm{BH}_{2} \mathrm{NH}_{2} \mathrm{BH}_{3}\right]^{-}$(VI) (VB: Verkade's base, 2,8,9-triisobutyl2,5,8,9-tetraaza-1-phospha-bicyclo[3.3.3] undecane), recently reported by the Sneddon group. ${ }^{17}$ In the structure of the anion $\mathrm{V}$, a $\mathrm{BH}_{3} \mathrm{NH}_{2} \mathrm{BH}_{2} \mathrm{NH}_{2}$ moiety adopts the anti conformation at one end of the anion and the gauche conformation at the other end. In the structure of the anion VI, the $\mathrm{BH}_{3} \mathrm{NH}_{2} \mathrm{BH}_{2} \mathrm{NH}_{2}$ moiety at both ends adopts the gauche form but the $\mathrm{NH}_{2} \mathrm{BH}_{2} \mathrm{NH}_{2} \mathrm{BH}_{2}$ moiety at the center adopts the anti form. In all anti structural parts, multiple intermolecular dihydrogen bonds were observed with the neighbouring anions but for each gauche form part, one intramolecular dihydrogen bond was observed $(2.30 \AA$ in the structure $\mathrm{V}$, and 2.17 and $2.32 \AA$ in structure VI before normalization of $\mathrm{B}-\mathrm{H}$ and $\mathrm{N}-\mathrm{H}$ bonds). ${ }^{17}$

The two gauche forms in our chunk and needle shaped crystals grown from the same solution would constitute a pair of enantiomers if the barrier to rotation around the $\mathrm{B}-\mathrm{N}$ bond is large. If the rotational barrier is small, these two structures would be rotational isomers. In either case, the absolute configurations (high rotational barrier) or absolute conformations (low rotational barrier) could not be determined from the $\mathrm{X}$-ray diffraction analysis alone, because of the absence of a heavy atom in the compound. ${ }^{18}$

In summary, crystal structures of DDAB were determined using single crystal X-ray diffraction analysis. The structures of both anti and gauche conformations of DDAB were observed and both inter- and intramolecular dihydrogen bonds were formed. Intermolecular dihydrogen bonds stabilize the anti form and an intramolecular dihydrogen bond stabilizes the gauche form. While the two stable staggered conformations of butane in the gas and the liquid phase are the anti and gauche forms and the superior stability of the anti conformer is ascribed to a combination of steric, electrostatic, and hyperconjugation effects, dihydrogen bonds play a dominant role in the rotational isomerization of the $\mathrm{B}-\mathrm{N}$ butane analogue, DDAB.

This work was supported by the U.S. Department of Energy, Office of Energy Efficiency and Renewable Energy, under Contract No. DE-FC3605GO15062. The authors are grateful to Prof. Thomas Evans for valuable comments.

\section{Notes and references}

1 (a) F. Weinhold, Nature, 2001, 411, 539; (b) V. Pophristic and L. Goodman, Nature, 2001, 411, 565; (c) R. A. Cormanich and P. F. Matheus, J. Org. Chem., 2009, 74, 8384; (d) P. R. Schreiner,
Angew. Chem., Int. Ed., 2002, 41, 3579; (e) F. Weinhold, Angew. Chem., Int. Ed., 2003, 42, 4188.

2 (a) J. Zheng, K. Kwak, J. Xie and M. D. Fayer, Science, 2006, 313, 1951; (b) Y. Mo, W. Mu, L. Song, M. Lin, Q. Zhang and J. Gao, Angew. Chem., Int. Ed., 2004, 43, 1986; (c) F. M. Bickelhaupt and E. J. Baerends, Angew. Chem., Int. Ed., 2003, 42, 4183; (d) K. P. Travis and D. J. Searles, J. Chem. Phys., 2006, 125, 164501; (e) R. Ishizuka and F. Hirata, Chem. Phys. Lett., 2006, 420, 135.

3 X. Chen, J.-C. Zhao and S. G. Shore, J. Am. Chem. Soc., 2010, 132, 10658.

4 (a) M. H. Matus, K. D. Anderson, D. M. Camaioni, S. T. Autrey and D. A. Dixon, J. Phys. Chem. A, 2007, 111, 4411; (b) W. R. Nutt and M. L. McKee, Inorg. Chem., 2007, 46, 7633; (c) V. S. Nguyen, M. H. Matus, D. J. Grant, M. T. Ngugen and D. A. Dixon, J. Phys. Chem. A, 2007, 111, 8844; (d) P. M. Zimmerman, A. Paul, A. Zhang and C. B. Musgrave, Inorg. Chem., 2009, 48, 1069.

5 R. H. Crabtree, Science, 1998, 282, 2000.

6 (a) M. P. Brown, R. W. Heseltine, P. A. Smith and P. J. Walker, J. Chem. Soc. A, 1970, 410; (b) M. P. Brown and R. W. Heseltine, J. Chem. Soc., Chem. Commun., 1968, 1551.

7 (a) T. B. Richardson, S. D. Gala and R. H. Crabtree, J. Am. Chem. Soc., 1995, 117, 12875; (b) W. T. Klooster, T. F. Koetzle, P. E. M. Siegbahn, T. B. Richardson and R. H. Crabtree, J. Am. Chem. Soc., 1999, 121, 6337.

8 V. I. Bakhmutov, Dihydrogen Bonding: Principles, Experiments, and Applications, Wiley, New Jersey, 2007.

9 (a) R. H. Crabtree, P. E. M. Siegbahn, O. Eisenstein, A. L. Rheingold and T. F. Koetzle, Acc. Chem. Res., 1996, 29, 348; (b) R. Custelcean and J. E. Jackson, Chem. Rev., 2001, 101, 1963; (c) I. Alkorrta, I. Rozas and J. Elguero, Chem. Soc. Rev., 1998, 27, 163; (d) A. Staubitz, A. P. M. Robertson and I. Manners, Chem. Rev., 2010, 110, 4079.

10 (a) S. G. Shore, C. W. Hickam Jr. and D. Cowles, J. Am. Chem. Soc., 1965, 87, 2755; (b) S. G. Shore and C. L. Hall, J. Am. Chem. Soc., 1966, 88, 5346; (c) J. F. Eastham, J. Am. Chem. Soc., 1967, 89, 2237; (d) S. G. Shore and C. L. Hall, J. Am. Chem. Soc., 1967, 89, 3947; (e) D. E. Young and S. G. Shore, J. Am. Chem. Soc., 1969, 91, 3497; (f) E. Mayer, Inorg. Chem., 1972, 11, 866; (g) P. Finn and W. L. Jolly, Inorg. Chem., 1972, 11, 1941; (h) E. Meyer, Inorg. Chem., 1973, 12, 1954; (i) R. W. Parry, J. Organomet. Chem., 2000, 614-615, 5.

11 X. Chen, X. Bao, J.-C. Zhao and S. G. Shore, J. Am. Chem. Soc., 2011, 133, 14172.

12 X. Chen, X. Bao, J.-C. Zhao and S. G. Shore, Chem.-Eur. J., 2012, DOI: $10.1002 /$ chem. 201201342 .

13 G. A. Jeffrey and W. Saenger, Hydrogen bonding in biological structure, Springer, Berlin, 1994.

14 H. Nöth and S. Thomas, Eur. J. Inorg. Chem., 1999, 1373.

15 C. A. Jaska, K. Temple, A. J. Lough and I. Manners, J. Am. Chem. Soc., 2003, 125, 9424.

16 H. C. Johnson, A. P. M. Robertson, A. B. Chaplin, L. J. Sewell, A. L. Thompson, M. F. Haddow, I. Manners and A. S. Weller, J. Am. Chem. Soc., 2011, 133, 11076.

17 W. C. Ewing, A. Marchione, D. W. Himmelberger, P. J. Carroll and L. G. Sneddon, J. Am. Chem. Soc., 2011, 133, 17093.

18 H. D. Flack and G. Bernardinelli, Chirality, 2008, 20, 681 